\title{
The conservation agriculture in northwest of Morocco (Merchouch area): The impact of no-till systems on physical properties of soils in semi-arid climate
}

\author{
Abdelali El Mekkaoui ${ }^{1,2, *}$, Rachid Moussadek ${ }^{1}$, Rachid Mrabet $^{1}$, Said Chakiri $^{2}$, Ahmed Douaik $^{1}$, Ahmed Ghanimi $^{3}$, and \\ Abdelmjid Zouahri ${ }^{1}$ \\ ${ }^{1}$ National Institute of Agronomic Research (INRA), CRRAR, URECRN, Department of Environment and Conservation of Natural \\ Resources - Rabat, Morocco \\ ${ }^{2}$ Ibn Tofail University, Faculty of Sciences, Natural Resources Geosciences Laboratory, Department of Geology, PO Box 133, Kénitra, \\ Morocco \\ ${ }^{3}$ Mohammed V University, Faculty of Sciences, Laboratory of Materials, Nanotechnologies and Environment, Av Ibn Batouta, PO Box \\ 1014, Rabat, Morocco
}

\begin{abstract}
Conservation agriculture $(\mathrm{CA})$ is characterized by three principles: minimum tillage, even the total absence of tillage in the case of direct seeding (NT), permanent soil cover by mulch, and diversification of crops. Its main objective is to control soil degradation by conserving the physical and biological properties and fertility of the soil, which leads to an improvement in productivity, while preserving the environment. Conventional tillage (CT) used in the arid and semi-arid environments of Morocco (particularly in the study site area of Merchouch) compromise the productivity of established crops in these regions. The work presented consists in the study of the impact of NT on the physicochemical properties of the soil, especially organic matter (SOM), bulk density (BD), soil moisture ( $\theta \mathrm{g}$ ), and structural stability (SS) in semi-arid zones. The results show that the use of the NT system positively influences the accumulation of SOM, especially at the soil surface horizon $(0-5 \mathrm{~cm})$. Concerning $\theta \mathrm{g}$, there is a significant difference between the two treatments (NT and CT) at the average of the three depths and especially at the horizon $20-40 \mathrm{~cm}$ so NT increases the water retention capacity. This study also shows that the mean weight diameter (MWD) of the 3 tests (water, ethanol, and rehumectation) is higher for NT compared to CT. This shows that no-till helped to build a good soil structure over time, which is highly desirable for improving agricultural productivity and conserving natural resources, especially water.
\end{abstract}

\section{Introduction}

The agricultural sector plays an important role in the growth of the Moroccan economy and constitutes a strong support to the country's development, since it represents up to $20 \%$ of the gross domestic product and employs about $40 \%$ of the active population [1]. Currently, the useful agricultural area (UAA) in Morocco represents about 9.2 million hectares, $65 \%$ of which is sown to cereals. However, this area must be reduced by $22 \%$ while increasing its production by $44 \%$ by 2020 within the framework of the new agricultural strategy (Green Morocco Plan) [2]. This poses a double challenge to this sector: ensuring food security for a population with an accelerated demographic growth and cushioning the degradation of agricultural land [3]. Agricultural activities based on intensive, so-called conventional tillage can cause problems of land erosion, water and soil pollution and desertification [4].

Furthermore, tilled soils are the most exposed to water erosion due to their low organic matter content, which increases the sensitivity of aggregates to the action of erosive agents [5]. This has been confirmed by the FAO, which carried out an exhaustive inventory on all the country's land and estimated that 9 million hectares of soil in agricultural areas and rangelands in Morocco are degraded [6]. In addition, Morocco's arid and semi-arid environments receive less and less rainwater due to climate change [7]. It is therefore advisable to review cultivation techniques by looking for agricultural management systems that allow for sustainable and technically acceptable agriculture, increasing and stabilizing yields while preserving soil resources. As a result, agronomists and researchers around the world have proposed alternatives to conventional tillage techniques and several agricultural strategies, based on the following principles of reduced tillage, appropriate crop rotation and crop residue management, have been considered and are known asConservation Agriculture (CA) systems. This system, which is still not widely adopted in Morocco, could offer solutions to the problems facing its agriculture, especially in areas marked by the presence of degraded soils and under the influence of climate change. Indeed,

\footnotetext{
*Corresponding author: abdelali.elmekkaoui10@gmail.com
} 
to mitigate the vulnerability of soils to the negative effects of climate change and improve their qualities and productivity, direct sowing constitutes an opportunity that has already proved its worth in several regions of the world [8].

It is in this context that this study, which aims to characterize the impact of cultural practices on soil structural stability, bulk density, moisture, and organic matter, is being conducted. Two types of tillage were compared: conventional seeding (CT) and direct seeding (NT), based on a chickpea-soft wheat rotation in the Zaër region.

\section{Materials and Methods}

\subsection{Research site and experiment set-up}

Merchouch experimental area is located in the province of Khémisset, Rommani circle, $68 \mathrm{~km}$ south-east of Rabat. It is located at $33.567^{\circ} \mathrm{N}$ latitude and $06.633^{\circ} \mathrm{W}$ longitude, and is $255 \mathrm{~m}$ above mean sea level (Figure 1).

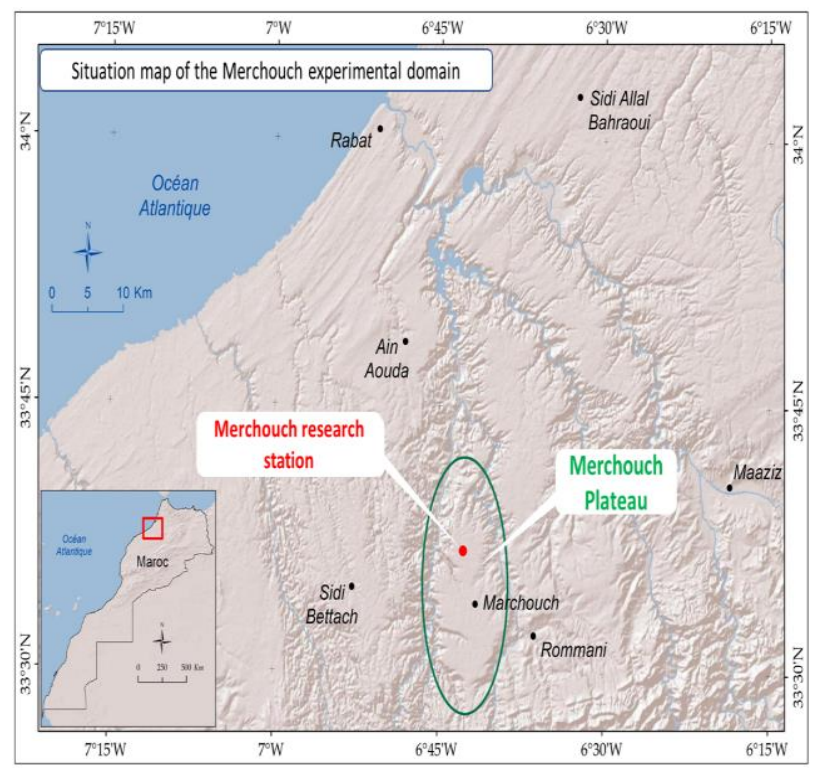

Fig. 1. Location of the study site in Morocco and the Zaer region

The studied soil is classified as Vertisols characterized by high clay mineral content $(>50 \%)$ [5], more soil characteristics are given in Table 1.

The regional climate is semi-arid with moderate winter precipitation. The long-term (40 years) average annual precipitation is $394 \mathrm{~mm}$ with a maximum of 665 $\mathrm{mm}$ and a minimum of $181 \mathrm{~mm}$. The average rainfall from 2017 to 2018 is only $295 \mathrm{~mm}$. Droughtis frequent at different stages of cultivation [9]. Average rainfall and air temperatures are shown in Figure 2.

The long-term trial has been installed on this site since 2005 on two adjacent plots, each with $200 \mathrm{~m}$ long and $100 \mathrm{~m}$ wide, to assess the effect of soil management on soil quality and crop production. The rotation practiced is leguminous (lentils, chickpeas...) / cereals (soft wheat, durum wheat...), it is among the most recommended rotations in the region. The treatments studied are: conventional tillage (TC) with stubble plow and cover crop, carried out in plots ploughed over the first few centimetres (10 to $15 \mathrm{~cm}$ deep) and direct seeding (SD) which consists of an opening of 2 to $3 \mathrm{~cm}$ from the ground to place the seed at a depth of $5 \mathrm{~cm}$, carried out by a special KUHN type seed drill. Since September 2005, the plots have been given the same technical itinerary (rotation, variety, sowing rate, dose and type of fertiliser). Wheat was sown on 22 December 2017 at a rate of $150 \mathrm{~kg} / \mathrm{ha}$. The variety used is Arrihane, which has a wide adaptation and a good productive potential. Fertilizers were brought on February $1^{\text {st }}, 2018$ following the recommendations of the National Institute of Agronomic Research in Rabat, $150 \mathrm{~kg} / \mathrm{ha}$ of 14-28-14 and $50 \mathrm{~kg} / \mathrm{ha}$ ammonium sulfate $21 \%$.Under no-till conditions, there are no tillage or soil preparation operations. In fact, the seed drill used places the seeds and fertilizers without any turning of thesoil.

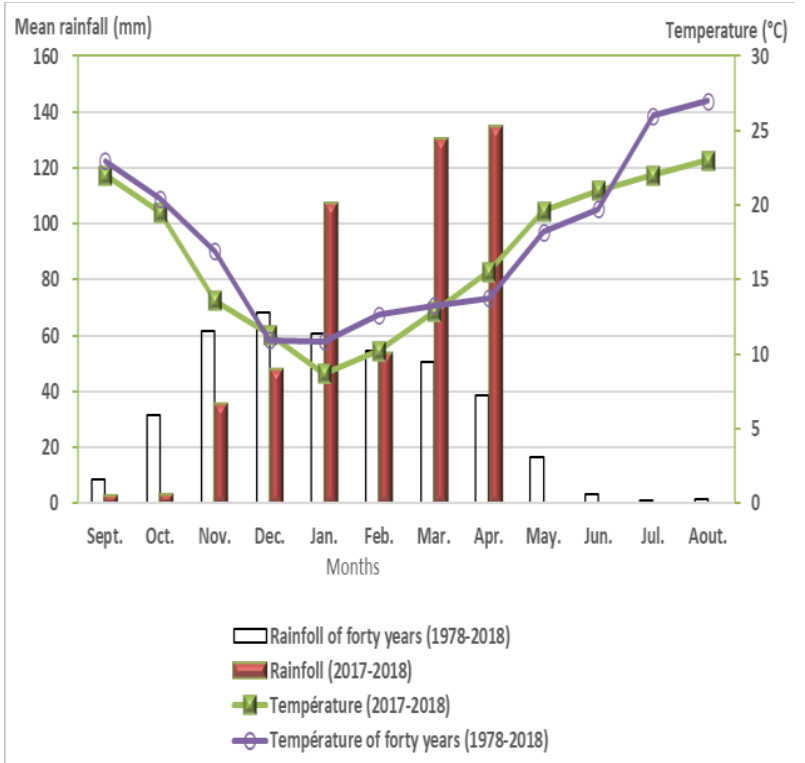

Fig.2.Ombrothermic diagram with normal monthly temperatures and rainfall during the 2017-2018 agricultural season compared to variations in annual rainfall data measured for forty years (1978-2018) at the Merchouch station

\subsection{Soil sampling and preparation for analysis}

In order to study the impact of SD on soil quality, soil samples were taken in February 2018 for the characterization of soil physico-chemical parameters. For this we used four types of sampling for this purpose 50 samples for physico-chemical analyses in the laboratory were thus made up of five replicates for each plot with five horizons (H1: 0-5 cm, H2 : 5 to $10 \mathrm{~cm}$, H3: 10 to $20 \mathrm{~cm}, \mathrm{H} 4: 20$ to $40 \mathrm{~cm}$, and $\mathrm{H} 5: 40$ to 60 $\mathrm{cm})$. Samples, in the form of superficial clods $(0-20 \mathrm{~cm})$ of five replicates for each plot, were placed in cardboard boxes bearing the sample identifier for the structural stability test (10 samples). Five replicates for each plot, with two depths per point $(0-13$ and $13-26 \mathrm{~cm})$ using a cylinder with a radius of $5.5 \mathrm{~cm}$ and a height of $12 \mathrm{~cm}$, were used for the bulk density test ( 20 samples). The soil characterization was carried out before the installation of 
the tests (beginning of December). Two crop profiles were excavated and described (Figure 4).

Samples taken in the field are received at the store, dried in the open air, crushed by hand and then sieved at $2 \mathrm{~mm}$ to remove plant debris and stones larger than 2 $\mathrm{mm}$. An aliquot of soil sieved at $0.2 \mathrm{~mm}$ is kept for analysis of organic matter and nitrogen. After this operation, the soil samples were placed in plastic bags bearing the laboratory code and are ready for the various physico-chemical soil analyses that were carried out at the Research Unit on the Environment and Conservation of Natural Resources at the Regional Centre for Agronomic Research, INRA Rabat. All analyses were carried out in duplicate.

\subsection{Soil granulometry and pedology}

Particle size is determined by sedimentation according to the Bouyoucos method[10]. All particles larger than 2 $\mathrm{mm}$ in diameter are removed on a 10 -mesh sieve. The sieved sample is homogenised and a weight of approximately $40 \mathrm{~g}$ (dry weight) is mixed with a volume of water containing a dispersing agent and introduced into a cylinder. Subsequently, the density of the mixture is measured with a hydrometer at various time intervals (30 seconds to 24 hours). The density obtained as a function of the sedimentation time gives the particle size of the sample analysed.

The soil profiles selected for this analysis PD1 and PD2 are located in plots NT and CT, respectively. The soil description was done according to the French Soil Classification (CPCS, 1967) [11].

\subsection{Soil moisture}

Soil moisture determines the diffusion or storage characteristics of water in the soil. Among the methods that determine soil moisture is the gravimetric method described by Gardner, 1986 [12]. which consists of drying the soil sample in an oven at $105^{\circ} \mathrm{C}$ for 24 hours. The weight loss after drying is equal to the moisture content of the soil:

$\theta g=\left(P_{\text {hum }}-P_{\text {sec }}\right) /$ Psec

with $\theta g$ : gravimetric humidity $(g / g)$, Phum: the wet weight $(g)$ and $P_{\text {sec: }}$ : weight of the dry soil obtained after drying $(g)$

\subsection{Structural stability}

Aggregate stability represents the ability of a soil to maintain its solid phase and porosity arrangement when exposed to stresses [13]. It is a property that accounts for the cohesion of soil aggregates. It is used to determine the susceptibility of soils to erosion processes. Structural stability (SS) depends on a number of factors, the most frequently mentioned being tillage, soil texture, organic matter (SOM), and the nature of the cations adsorbed on the clay-humus complex $[14,15,16]$.

The method used is that proposed by Le Bissonnais and Le Souder (1995) [17]. This method is applied to $3.15-5 \mathrm{~mm}$ aggregates separated by sieving, air-dried and stored dry. Three tests are applied to these aggregates under the different climatic, hydric and structural conditions that can be encountered on the soil surface:

a- Fast moistening,

b- Slow re-humectation,

c- Mechanical disintegration.

The results are expressed in terms of mean weight diameter (MWD) calculated according to:

$\mathrm{MWD}=\Sigma \overline{\mathrm{X}}_{\mathrm{i}} * \mathrm{Wi}$

with $\overline{\mathrm{X}} \mathrm{i}$ : Average diameter of two successive sieve classes and Wi: proportion of the total mass of residual aggregate in each sieve $(2,1,0.5,0.2,0.1$, and $0.05 \mathrm{~mm})$.

Which becomes, for the sieves used:

$M W D=((3.5 \times[\%>2 \mathrm{~mm}])+(1.5 \times[\% 1$ to $2 \mathrm{~mm}])$

$+(0.75 \times[\% 0.5$ to $1 \mathrm{~mm}])$

$+(0.35 \times[\% 0.2$ to $0.5 \mathrm{~mm}])$

$+(0.15 \times[\% 0.1$ to $0.2 \mathrm{~mm}])$

$+(0.075 \times[\% 0.05$ to $0.1 \mathrm{~mm}])$

$+(0.025 \times[\%<0.05 \mathrm{~mm}])) / 100$

The higher the MWD of a soil, the greater its structural stability.

\subsection{Bulk density}

Soil bulk density is an indicator of soil compaction and total soil porosity [18]. It was measured by Grossman and Reinsch (2002)[19], calibrated cylinder method.

From each of the two treatments (SC and SD) of the undisturbed cylinders were takenat two depths (0-13 and 13-26 cm) and with five repetitions: These cylinders were weighed and left in the oven $\left(105^{\circ} \mathrm{C}\right)$ for 24 hours and reweighed to obtain the percentage of the weight of the water in relation to the weight of the dry soil. The latter is brought back to the volume of the cylinder to have the apparent density of the sample. Knowing the total volume as well as the mass of the soil, the apparent density is determined by the following relation:

$\mathrm{Da}=\mathrm{Ms} / \mathrm{VT}$

Da: Bulk density $(\mathrm{g} / \mathrm{cm} 3)$

Ms: Dry soil mass (g)

$V T$ : Total soil volume $(\mathrm{cm} 3)$

\subsection{Organic matter}

Soil organic matter (SOM) content is an important parameter for measuring soil quality. It has a significant influence on the maintenance of physical, chemical and biological properties and plays multiple roles [20-21]. Increasing the amount of SOM in the soil can therefore have a significant effect on atmospheric $\mathrm{CO} 2$ concentrations, by limiting part of the greenhouse gas emissions [22]. Soil organic carbon (SOC) has been assessed using the classic method of Walkley and Black [23] in which carbon oxidation is carried out cold. The carbon in the organic matter present in the soil sample is oxidized by mixing $1 \mathrm{~N}$ potassium dichromate $\left(\mathrm{K}_{2} \mathrm{Cr}_{2} \mathrm{O}_{7}\right)$ in a sulphuric medium $\left(\mathrm{H}_{2} \mathrm{SO}_{4}\right)$ until $\mathrm{CO}_{2}$ is released. The excess of dichromate not used in the reaction is determined with $0.5 \mathrm{~N}$ Mohr salt in the presence of diphenylamine and sodium fluoride $(\mathrm{NaF})$. The total carbon measured ( $\mathrm{C}$ in \%) makes it possible to estimate the percentage of SOM by the formula:

$\operatorname{SOM}(\%)=\mathrm{C}(\%) * 1.724$ 
The results of the SOM were expressed in $\%\left(\mathrm{~g}_{100 \mathrm{~g}^{-1} \text { of }}\right.$ the soil sieved to $0.2 \mathrm{~mm}$ ).

\subsection{Statistical analysis}

The data were statistically analyzed for the five depths and at different soil parameters using the GLM (general linear model) procedure of the statistical analysis system (SAS version, 2009). The statistical method of analysis of variance (ANOVA) was used to find the significance of the effects of the two treatments (NT and CT) and the different depths on soil quality attributes. Multiple comparison of means was performed using Duncan's test at a 5\% significance level [24].

\section{Results and discussion}

\subsection{Soil granulometry and pedology}

The soil study at the experimental site showed that the soil type is a Vertisol with possible external drainage as shown in the SP profile (Fig. 3).

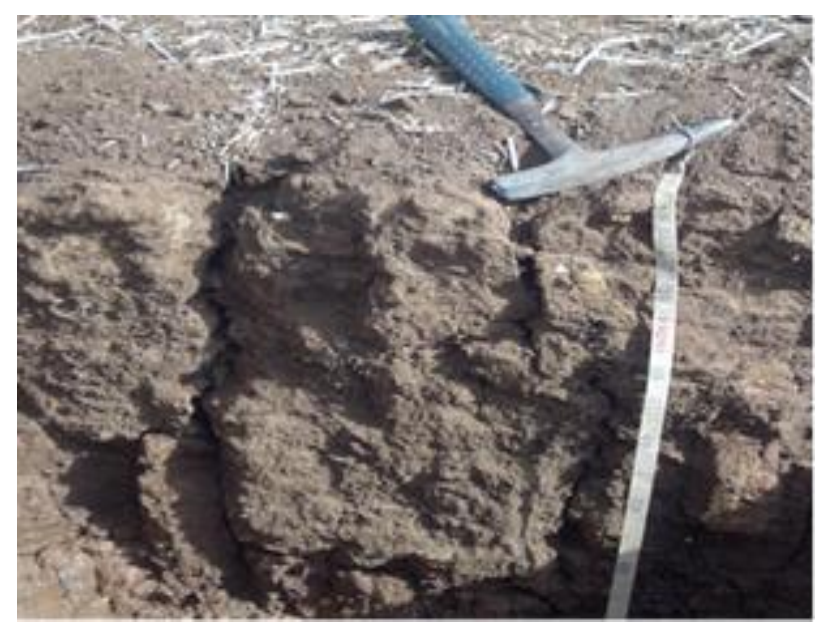

Fig. 3. Soil profile description : SP.

- SP profile, the slope is less than $1 \%$, drainage is moderate toreduced and the residue is chickpea stubble.

Soil type: vertisols with external drainage possible.

$0-20 \mathrm{~cm}$ : dry, colour $10 \mathrm{YR} 3 / 2$, clay texture, low effervescence, fine and medium polyhedral structure, presence of shrinkage slits 1 to $2 \mathrm{~cm}$ wide, spaced 10 to $20 \mathrm{~cm}$ apart, porous with many fine and medium roots, diffuse transition.

Low effervescence, well-developed coarse polyhedral structure, slit 1 to $2 \mathrm{~cm}, 10$ to $30 \mathrm{~cm}$ apart, many fine and medium roots and rootlets, diffuse transition.

40 - $90 \mathrm{~cm}$ : dry, colour $10 \mathrm{YR} 4 / 2$, very fine clay texture, coarse to medium prismatic polyhedral structure, moderately developed slide faces, low effervescence, shrinkage cracks, porous, fine rootlets, diffuse transition.

90 - $140 \mathrm{~cm}$ : dry, lively effervescence, clayey, iron and manganese pisolites, calcareous crust.

Table 1 shows that the soil at the Merchouch site is a Vertisol (calcareous brown Chernozem), rich in clay ( $>50 \%$ clay).

Comparative Table 2 shows the average clay, silt and sand content in the five sampling depths $(0-5,5-10,10$ 20, 20-40 and 40-60 cm) for the systems (NT and CT).

The two plots studied show that the soil studied has an identical clay texture.

\subsection{Soil moisture}

The choice of sowing mode (NT or CT) is essentially based on its capacity to allow the soil to store water and make it available to the roots, especially in an arid sowing climate [25].

Measurements of soil moisture content under the two treatments (NT and CT) were observed during the $2017 / 2018$ crop year during the wheat growing cycle (by stage), significant differences were observed between the two treatments (NT and CT) at the average of the three depths and especially at the $20-40 \mathrm{~cm}$ horizon (Fig. 4).

The unploughed plots have a moisture content that increases from $23 \%$ on the surface to $25 \%$ at depth, which shows that NT provides better water retention than CT in areas with low rainfall. Under direct seeding, the unloosened surface and the plant residues on it slow down evaporation, so the surface horizon is often less dry and the deeper horizon also retains more moisture, which clearly shows that this system makes it possible to conserve water reserves [26]. Contrary, with tillage, plant residues are buried and the exposed surface of the tilled soil is much larger, resulting in greater evaporation of water from the upper horizon.

Table 1. Soil profile texture (SP)

\begin{tabular}{|c|c|c|c|c|c|c|c|}
\hline Profile - Field & Duration & $\begin{array}{l}\text { Soil depth } \\
\text { (cm) }\end{array}$ & Clay (\%) & Silt (\%) & Sand $(\%)$ & $\begin{array}{l}\text { Limestone } \\
\text { Total (\%) }\end{array}$ & Texture \\
\hline \multirow{4}{*}{ SP-Site Merchouch } & \multirow{4}{*}{13 years } & $0-20$ & 51.0 & 36.1 & 12.7 & 2.8 & \multirow[t]{4}{*}{ Clay } \\
\hline & & $20-40$ & 50.2 & 38.6 & 11.2 & 3.3 & \\
\hline & & $40-90$ & 52,5 & 35.1 & 12.4 & 13.5 & \\
\hline & & $90-140$ & 53 & 32.1 & 14.9 & 18.5 & \\
\hline
\end{tabular}


Table 2. Soil grain size characteristics for NT and CT systems

\begin{tabular}{|c|c|c|c|}
\hline & Texture (\%) & NT & CT \\
\hline \multirow{6}{*}{$\begin{array}{l}\% \text { on dry } \\
\text { fine soil }\end{array}$} & Clay & 52.5 & 52.1 \\
\hline & Fine slit & 13.0 & 14.4 \\
\hline & Coarse slit & 13.3 & 12.9 \\
\hline & Fine sand & 8.9 & 8.2 \\
\hline & Coarse sand & 5.1 & 4.3 \\
\hline & Limestone & 2.6 & 3.2 \\
\hline \multirow{3}{*}{$\begin{array}{c}\% \text { on the } \\
\text { mineral part }\end{array}$} & Clay & 55.7 & 55.9 \\
\hline & Slit & 28.9 & 30.3 \\
\hline & Sand & 15.4 & 13.8 \\
\hline \multicolumn{2}{|c|}{ Type of soil } & \multicolumn{2}{|c|}{ Vertisol } \\
\hline
\end{tabular}

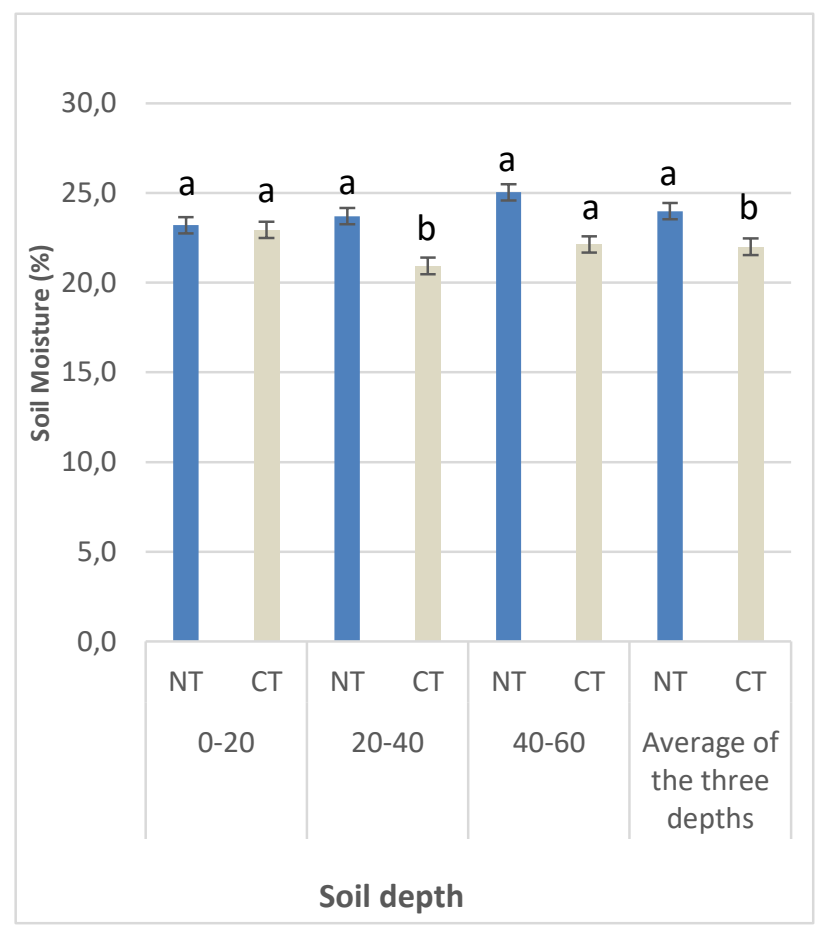

Fig. 4. Effect of the two cultural practices (NT and CT) on humidity in percentage. Treatments with the same letter are not significantly different according to Duncan's test $(\mathrm{P}<0.05)$.

\subsection{Structural stability}

The structural stability of a soil corresponds to the capacity of a soil to maintain its arrangement between solid and empty particles when it is exposed to various stresses, such as the disaggregating action of raindrops or moistening [27]. It is a physical property of soils indicative of their vulnerability to threshing and erosion [28-5].

The results of the soil structural stability tests (Fig. 5) show that there is a significant difference between the two practices for the three tests. This result shows that Merchouch vertisol can still better resist aggregate bursting following rapid rewetting. For the slow remoistening test, the soil under direct seeding shows a
MWD value equal to $1.8 \mathrm{~mm}$, significantly higher than for soils under CT $(0.6 \mathrm{~mm})$.

This shows that, under direct seeding, the presence of residues improves soil resistance under slow wetting that simulates the effect of moderate rainfall. Similarly, in the ethanol test, the stability of the aggregates was higher under NT than under CT. These results confirm those obtained by Laghrour et al. 2016 [29], on the same trial under NT for 3 years (after 10 years of direct seeding).

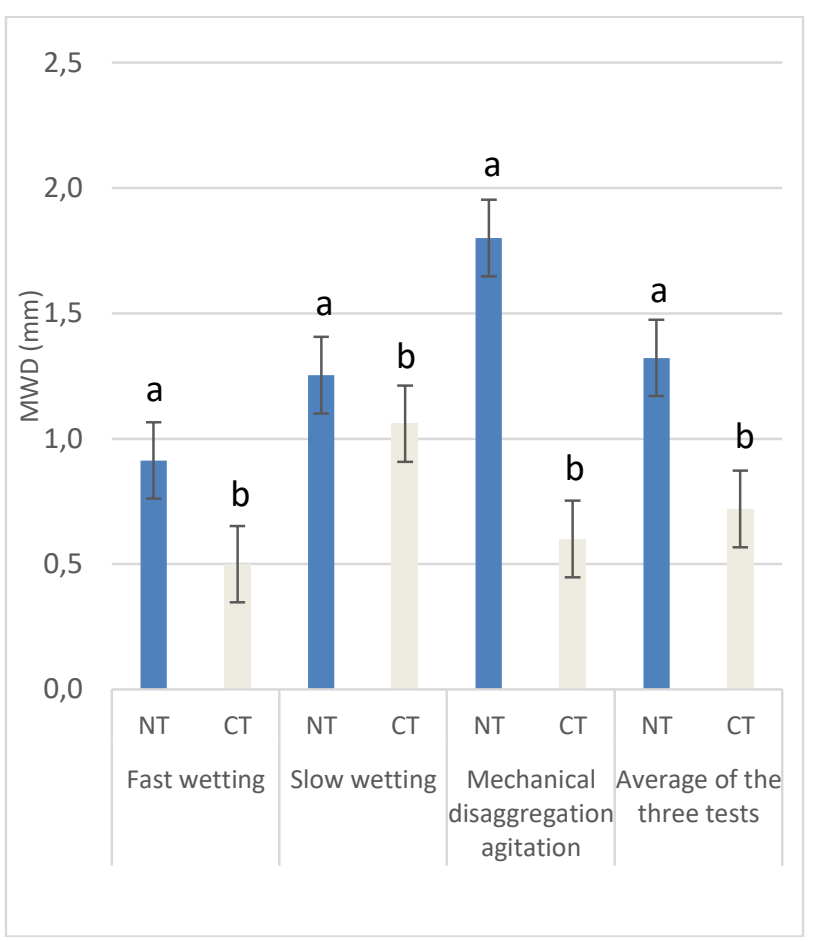

Fig. 5.Effect of tillage on Mean Weight Diameter (MWD) for three tests (Fast wetting, Slow wetting and Mechanical disaggregation) on the soil surface $(0-20 \mathrm{~cm})$.

However, in another study, it can be concluded that plots under CT have a low structural stability (MWD $<0.8 \mathrm{~mm}$ ) whereas plots under NT have a more stable structure (MWD $>0.8 \mathrm{~mm}$ ) according to the standards developed by Le Bissonnais (1996) [27]. Laghrour et al. (2015) [30], showed that there is a significant difference for the slow wetting and rapid wetting tests while there is no significant difference for the mechanical disintegration test. On the other hand, the results obtained by Moussadek et al (2011) [5], on the same site showed that there is a significant difference for the slow wetting test while there is no significant difference for the other two tests. Comparing these results with ours, we can conclude that the effect of direct seeding on SOM accumulation and improvement of structural stability appears only after a number of years and that after 13 years under NT, in the semi-arid conditions of Morocco Merchouch Vertisol can still resist better to the different pedoclimatic stresses compared to CT (Fig. 5).

\subsection{Bulk density}

Bulk density is an indicator of soil compaction and porosity. Fig.6 shows that the bulk density in NT is 
slightly higher than that obtained in CT over the $0-13 \mathrm{~cm}$ depth and even over the $13-26 \mathrm{~cm}$ depth, this difference is not significant. This can be explained by a loosened soil reflecting the mixing and decompaction action of the CT on the first $7 \mathrm{~cm}$ of the soil. On the other hand, in NT, there was less disturbance below the seedbed, causing a more compacted horizon.

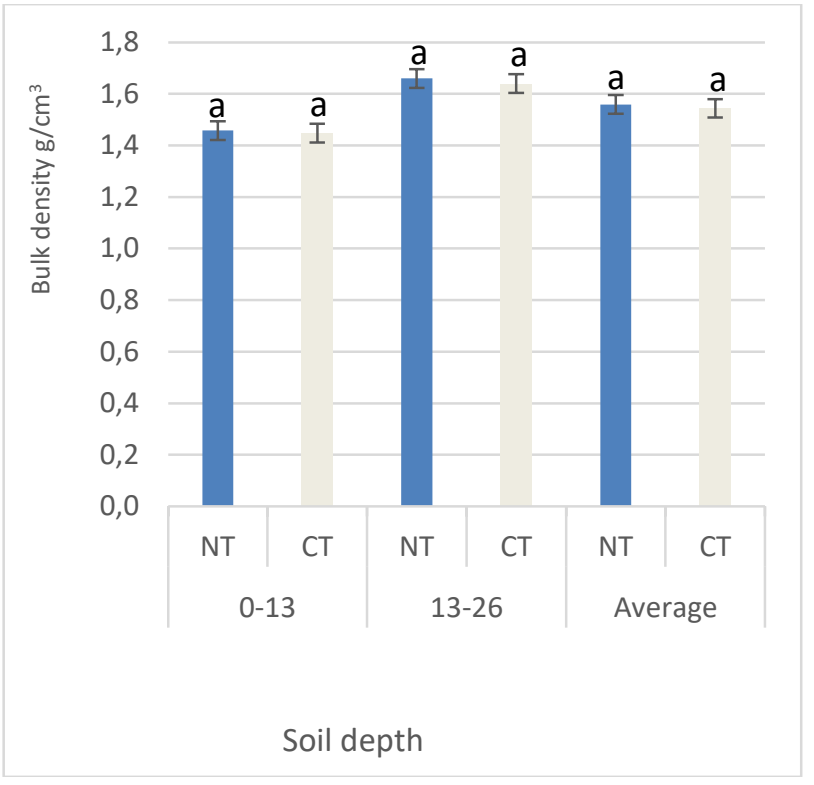

Fig. 6. Effect of tillage on bulk density in the 0-13 and 13-26 $\mathrm{cm}$ depth for NT and CT.

These results confirm those obtained by Moussadek et al (2011) [5], on the same site but invalidate those of Laghrour et al (2015)[30] and Laghrour et al (2016) [29] who found a significant difference between the two systems with bulk density< 1.34 (Table 3 ).

This improvement in bulk density could only be observed after thirteen years of installation of the NT system.
According to Fig. 6 and Table 3, bulk density was high under NT $\left(>1.4 \mathrm{~g} \mathrm{~cm}^{-3}\right)$ and reached $1.66 \mathrm{~g} \mathrm{~cm}^{-3}$ under NT in 13-26 cm. For Vertisols used in agriculture, bulk density can be as high as $2 \mathrm{~g} \mathrm{~cm}^{-3}$ due to their swelling clay content (Murthy et al., 1982)[31], since the soil surface bulk density $(0-13 \mathrm{~cm})$ was slightly higher in no-till $\left(1.5 \mathrm{~g} \mathrm{~cm}^{-3}\right)$ than the soil surface bulk density $(1.5$ $\left.\mathrm{g} \mathrm{cm}^{-3}\right)$ in the soil surface $(0-13 \mathrm{~cm})$.

It was slightly higher in no-till $(1.5 \mathrm{~g} \mathrm{~cm}-3)$ than in conventional tillage $(1.4 \mathrm{~g} \mathrm{~cm}-3)$, Obtained by sowing with conventional tillage $\left(1.4 \mathrm{~g} \mathrm{~cm}^{-3}\right)$ : This is consistent with the work of several authors [32-33] who have shown that under NT, the bulk density is higher over 75 $\mathrm{cm}$ of the soil profile compared to the CT.This leads to the conclusion that no-till increases clay soil compaction, but several authors believe that this compaction under NT decreases over time following the intensification of biological activity under NT [34]. Indeed, wildlife finds a habitat for intense biological activity and for development of its biomass in the soil.

\subsection{Organic matter}

At the Merchouch site, the SOM content is higher in NT than in CT at all depths. According to Duncan's statistical control test,the difference in SOM content between CT and NT is significant at all depths. The SOM content decreases with depth because the crop residues are not buried and decompose at the surface. The SOM content in CT that is always lower than in NT may be due to higher CT mineralization.

The results for the SOM may explain those obtained for structural stability $(0-13 \mathrm{~cm})$ at this site. These results corroborate those obtained by Moussadek et al (2011) and Laghrour et al (2014)on the same site and show that the improvement in SOM content depends on how long it takes to adopt the NT.

Table 3. Effect of both cultural practices on bulk density over time

\begin{tabular}{|c|c|c|c|c|}
\cline { 2 - 5 } \multicolumn{1}{c|}{} & $\begin{array}{c}\mathbf{2 0 1 1} \\
\text { Moussadek et al (2011) }\end{array}$ & $\begin{array}{c}\mathbf{2 0 1 5} \\
\text { Laghrour et al (2015) }\end{array}$ & Laghrour et al (2016) & $\mathbf{2 0 1 8}$ \\
\hline NT (0-13 cm) & $1.51(\mathrm{NT} 50)$ & 1.33 & 1.29 & 1.46 \\
\hline CT $(\mathbf{0 - 1 3} \mathbf{~ c m})$ & 1.45 & 1.12 & 1.15 & 1.45 \\
\hline
\end{tabular}

Table 4. Effect of tillage on SOM content

\begin{tabular}{|c|c|c|c|c|c|}
\hline \multirow{2}{*}{ Field } & Number of NT adoption years & \multirow{2}{*}{ Soil depth (cm) } & \multicolumn{2}{|c|}{ Soil organic matter (\%) } & \multirow{2}{*}{ Rate of change (\%) } \\
\cline { 3 - 5 } & & $0-5$ & $1.81 \pm 0.24 \mathrm{a}$ & $1.35 \pm 0.14 \mathrm{~b}$ & 34 \\
\hline \multirow{2}{*}{$\begin{array}{c}\text { Site of } \\
\text { Marchouch }\end{array}$} & \multirow{2}{*}{$\mathbf{1 3}$ years } & $5-10$ & $1.68 \pm 0.31 \mathrm{a}$ & $1.37 \pm 0.16 \mathrm{~b}$ & 23 \\
\cline { 3 - 5 } & & $10-20$ & $1.55 \pm 0.27 \mathrm{a}$ & $1.25 \pm 0.18 \mathrm{~b}$ & 24 \\
\cline { 3 - 6 } & & $20-40$ & $1.43 \pm 0.21 \mathrm{a}$ & $1.10 \pm 0.24 \mathrm{~b}$ & 29 \\
\cline { 3 - 5 } & & $40-60$ & $1.25 \pm 0.18 \mathrm{a}$ & $1.00 \pm 0.26 \mathrm{~b}$ & 26 \\
\hline
\end{tabular}




\section{Conclusion}

The objective of this study was to study the effect of direct seeding on the physico-chemical properties of the soil in the pedoclimatic situations of the Zaërs: Merchouch region. The study also allowed us to verify the actual existence of changes in the distribution of physical and chemical properties of the soil under direct seeding compared to conventional tillage, in the direction of improvement in general, especially in the surface horizon, especially with regard to SOM content. This improvement trend was more palpable at the Merchouch site, which had undergone a fairly long conversion period to the direct seeding system (13 years). In this sense, we reported a significant improvement in structural stability through direct seeding, which increases the organic matter content and microbial activity in the soil.For the apparent soil density; we noted that it is slightly higher in direct seeding than in conventional tillage at both depths $0-13$ and $13-26 \mathrm{~cm}$, with a non-significant difference between the two systems. We reported a decrease in bulk density over time in the SD system for the period 2011 to 2018. This decrease is explained by increased biological activity that improves soil aeration and reduces compaction. Our positive no-till results, although limited, encourage the continuation of this long-term study under conditions of good management of the installed crops.

\section{References}

1. N.Akesbi, Evolution et perspectives de l'agriculture marocaine. In Rapport 50 ans du développement humain et perspectives 2025. 85-198. Casablanca : Editions Maghrébines (2006)

2. M. Badraoui, \& R. Dahan, The Green Morocco Plan in relation to food security and climate change, in. Solh, M., Saxena, M.C. (Eds.), Proceedings of International Conference on Food Security and Climate Change in the Dry Areas, 1-4 February, Amman, Jordan, ICARDA Publication. 61-70, (2010)

3. R. Mrabet, R. Moussadek, A. Fadlaoui \& E. Van Ranst, Conservation agriculture in dry areas of Morocco. Field Crops Research. 132, 84-94, (2012)

4. T. Friedrich, A. Kassam et R. Mrabet, Sept/Déc HTE agriculture de conservation dans le monde : défis et évolutions $N^{\circ}$ 149/150 - p 10 (2011)

5. R. Moussadek, R. Mrabet and R. Dahan, Effet de l'agriculture de conservation sur la qualité des sols au Maroc, Revue H. T. E, 149/150, 2011b, 25-28, (2011)

6. A. Ouassou, T. Amziane, \& L. Lajouad, State of natural resources degradation in Morocco and plan of action for desertification and drought control. In Desertification in the Mediterranean Region. In Kepner, W. G. Rubio, J. L. Mouat, D. A. \& Pedrazzini, F. (Eds.). Security Issue. Dordrecht, Netherlands. Springer. 253p. (2006)
7. F. Driouech, M. Déqué, \& E. Sánchez-Gómez, Weather regimes-Moroccan precipitation link in a regional climate change simulation. Glob. Planet Change. 72, 1-10, (2010)

8. J. K. Syers, E. T. Craswell, \& P. Nyamudeza, Research needs and opportunities for farming Vertisols sustainability. In Syers, J. K., Penningde Vries, F. T., Nyamudeza, P. (Eds.). The Sustainable Management of Vertisols. CAB International Publishing, 283-290, (2001)

9. M.YACOUBI, M. EL MOURID, N. CHBOUKI, C. STOCKLE, Typologie de la sécheresse et recherche d'indicateur d'alerte en climat semi-aride marocain, 9, 269-276, (1998)

10. Centre d'expertise en analyse environnementale du Quebec, Détermination de la granulométrie dans les sols agricoles et les sédiments : méthode Bouyoucos, MA. 205 - GRA 1.0, Ministère de l'Environnement du Québec, 16 p. (2003)

11. C.P.C.S.,1967(Commission de Pédologie et de Cartographie des Sols). Classification des sols. Laboratoire des Géologie-Pédologie ENSA Grignon. Mimeo. 87p (1967)

12. W. H. Gardner, Water content. In: A. Klute (Eds), Methods of Soil Analysis Part 1: Physical and Mineralogical Methods. 2nd ed vol 9, USA : Am. Soc. Agron, pp. 493-544, (1986)

13. T. Pojasok, and B.D Kay, Assessment of a combination of wet sieving and turbidimetry to characterize the structural stability of moist aggregates. Can. J. Soil Sci.70 : 33-42, (1990)

14. D. King, and Y. Le Bissonnais, Rôle des sols et des pratiques culturales dans l'infiltration et l'écoulement des eaux. Exemple du ruissellement et de l'érosion sur les plateaux limoneux du nord de l'Europe. Comptes Rendus de l'Académie d'Agriculture de France, 78 : 91-105, (1992)

15. Y. Le Bissonnais, and D. Arrouays, Aggregate stability and assessment of soil crustability and erodibility. II. Application to humic loamy soils with various organic carbon contents. European Journal of Soil Science, 48 : 39- 48, (1997)

16. C. Chenu, Y. Le Bissonnais, and D. Arrouays, Organic matter influence on clay wettability and soil aggregate stability. Soil Science Society of America Journal, 64: 1479-1486, (2000)

17. Y. Le Bissonnais, et C. Le Souder, Mesurer la stabilité structurale des sols pour évaluer leur sensibilité à la battance et à l'érosion. Etude et gestion des sols, 2 : 43-56, (1995)

18. S. Alongo, \& F. Kambele, Évolution de la densité apparente et du rapport $\mathrm{c} / \mathrm{n}$ du sol sous les variétés exotiques et locale de manioc dans les conditions naturelles de Kisangani (R.D.Congo). Annales de l'Institut Facultaires des sciences agronomiques de Yangambi, Volume 1, pp. 197-214, (2013)

19. R.B. Grossman, and T.G. Reinsch, Bulk Density and Linear Extensibility: Core Method. In: Dane, J.H. 
and Topp, G.C., Eds., Methods of Soil Analysis. Part 4, Physical Methods, SSSA, Incorporated, Madison, 208-228, (2002)

20. A. Duprarque, P. Rigalle, Composition des MO et turn over ; Rôles et fonctions des MO, actes du colloque « Gestion de l'état organique des sols », 27 janvier 2011, Agro transfert (2011)

21. C.Mathieu, F.Pieltain, Analyse chimique des sols : méthodes choisies. (T. \&. Lavoisier, Éd.), (2003)

22. B.VanWESEMaEL, La séquestration et les émissions de gaz à effet de serre provenant des écosystèmes terrestres. Dossier scientifique réalisé dans le cadre de l'élaboration du Rapport analytique 2006-2007 sur l'état de l'environnement. Département de Géographie, Université catholique de Louvain. Louvain-la-Neuve. 19 p. (2006)

23. D.W. Nelson, L.E. Sommers, Total carbon, organic carbon,and organic matter. In: Page, A.L., et al. (Eds.), Methods of Soil Analysis, Part 2, 2nd Edition. Agronomy, Vol. 9. Soil Science Society of America, Madison, WI, pp. 539-579, (1982)

24. G.W. Snedecor, and W.G. Cochran, Statistical Methods. 7th Edition, Iowa State University Press, Ames, (1980)

25. Z. Abdellaoui, H. Teskrat, A. Belhadj, O. Zaghouane, Étude comparative de l'effet du travail conventionnel, semis direct et travail minimum sur le comportement d'une culture de blé dur dans la zone subhumide. Les actes des 4e Rencontres Méditerranéennes du Semis Direct. Sétif Algérie 3, 4,5 mai 2010. $\mathrm{N}^{\circ}$ special revue Recherche agronomique. pp : 68-82, (2010)

26. A. Chervet, L. Ramseier, W. G. Sturny, P. Weisskopf, U. Zihlmann, M. Müller et R. Schafflützel, Humidité du sol en semis direct et sous labour. Revue suisse Agric. 38(4) : pp 185-192. (2006)

27. Y. Le Bissonnais, "Aggregate stability and assessment of soil crustability and erodibility : I.Theory and methodology," European Journal of Soil Science, vol. 47, no. 4, pp. 425-437, (1996)

28. C. Chenu, S. Abiven, M. Annabi, S. Barray, M. Bertrand, F. Bureau, D. Cosentino, F. Darboux, O. Duval, L. Fourrié, C. Francou, S. Houot, C. Jolivet, K. Laval, Y. Le Bissonnais, L. Lemée, S. Menasseri, J.P. Pétraud, B. Verbèque Etude et Gestion des sols. 18, 161, (2011)

29. M. Laghrour, R. Moussadek, R. Mrabet, R. Dahan,M. El-Mourid, A. Zouahri, and $\mathrm{M}$. Mekkaoui, Long and Midterm Effect of Conservation Agriculture on Soil Properties in Dry Areas of Morocco, in Applied and Environmental Soil Science December (2016)

30. M. Laghrour, R. Moussadek, M. Mekkaoui, A. Zouahri, R. Dahan \& M. El Mourid, Impact du semis direct sur les propriétés physiques d'un sol argileux au Maroc Central (Impact of No Tillage on physical proprieties of a clay soil in Central
Morocco). J. Mater. Environ. Sci.6 : 391-396. (2015)

31. R. S. Murthy, J. C. Bhattacharjee, R. J. Landey, \& R. M. Pofali, Distribution, characteristics and classification of Vertisols. Pages 3-22 in Vertisols and rice soils of the tropics. 12th International Congress of Soil Science, New Delhi, India, (1982)

32. R. R. Bruce, G. W. Langdale, \& A. L. Dillard, Tillage and crop rotation effect on characteristics of a sandy surface soil. Soil Sci. Soc. Am. J. 54.17441747, (1990)

33. D. K. Cassel, C. W. Raczkowaki, \& H. P. Denton, Tillage effect on corn production and soil physical conditions. Soil Sci. Soc. Am. J. 59.1436-1443, (1995)

34. A. Jordan, L. M. Zavala, \& J. Gil, Effect of mulching on soil physical properties and runoff under semi-arid conditions in southern Spain. Catena. 81. 77-65, (2010). 